Revista da Seção Judiciária do Rio de Janeiro

\title{
CRIME E CASTIGO: JUSTIÇA, PUNIÇÃO E PERDÃO NAS CANTIGAS DE SANTA MARIA DE AFONSO X (SÉCULO XIII)
}

\section{CRIME AND PUNISHMENT: JUSTICE, PUNISHMENT AND FORGIVENESS IN THE CANTIGAS DE SANTA MARIA DE ALFONSO X (13TH CENTURY)}

\author{
Guilherme Antunes Junior ${ }^{1}$
}

Resumo: $O$ presente trabalho tem como objetivo comparar quatro relatos que fazem parte das Cantigas de Santa Maria com a obra legislativa Siete Partidas, ambas sob direção do rei de Castela e Leão Alfonso X. A escolha das cantigas se deve ao fato de elas abordarem quatro crimes: o homicídio, o roubo, a agressão física e a calúnia. Todas essas transgressões estão previstas nas normativas alfonsinas. A partir da comparação, buscarei analisar os papéis de Maria ao conceder perdão aos criminosos, evidenciando um contraste com a expansão dos códigos legislativos civis e os poderes seculares. Para tanto, são de suma importância as reflexões de Paul Ricoeur acerca da justiça, o legal e a bondade.

Palavras-chave: Alfonso X. Idade Média. Justiça. Perdão.

Abstract: This paper aims to compare four reports that are part of the Cantigas de Santa Maria with the legislative work Siete Partidas, both under the direction of the king of Castile and Leo Alfonso X. The choice of the cantigas is due to the fact that they address four crimes, murder, robbery, assault and calumny. All these transgressions are provided for in Alfonsin's regulations. From the comparison, I will seek to analyze the roles of Mary in granting forgiveness to criminals, evidencing a contrast with the expansion of civil and secular legislative codes. To this end, Paul Ricoeur's reflections on justice, law and goodness are of the utmost importance.

Keywords: Alfonso X. Middle Ages. Justice. Forgiveness.

Recebido em: $15 / 10 / 2021$ Aceito para publicação em: 08/11/2021

\footnotetext{
${ }^{1}$ Professor de História, Doutor em História Comparada pelo PPGHC - UFRJ Colaborador do Programa de Estudos Medievais (PEM - UFRJ).
} 
Revista da Seção Judiciária do Rio de Janeiro

\section{INTRODUÇÃO}

Este texto busca um ponto de reflexão sobre amor e justiça a partir de um texto específico de Paul Ricoeur, Lo justo entre lo legal y lo bueno, e as histórias de intervenções miraculosas existentes nas Cantigas de Santa Maria, de Alfonso X. Ao verificar que diversas cantigas são marcadas pela transgressão, há que se questionar se, na busca por justiça para proteção dos personagens cristãos, alguma diretriz específica da obra legislativa alfonsina serviu como parâmetro legal. Diversas cantigas do códice Rico tratam de crime e perdão de forma mais específica, apesar de os temas se interporem e uma mesma cantiga vir a ter enredo variado.

As Cantigas de Santa Maria (CSM) representam um conjunto heterogêneo de poemas caracterizados pelas intervenções miraculosas de Maria, daí também chamadas de cantigas de milagres, visto que existem outras cantigas medievais qualificadas por outros gêneros poéticos, como as cantigas de amor, de amigo, de escárnio e maldizer. As CSM que analiso, a fim de refletir acerca do amor, da justiça, da punição e do perdão seguem o repertório selecionado por Filgueira Valverde e classificadas como sendo de castigo e perdão (1985, p. LXIII) ${ }^{2}$. Assim, seguindo os apontamentos do mestre espanhol, compreendo que a temática central dessas narrativas tem a busca por justiça divina como reparadora da ordem em contraste com a justiça secular.

Essas análises são produto de algumas reflexões de Paul Ricoeur acerca da justiça como estrutura conflitante marcada por uma debilidade inerente: a relação dialética entre o bom e o legal: "la dialéctica de lo 'bueno' y de lo 'legal' es inherente al papel de idea reguladora que puede ser asignado [atribuído] a la idea de justicia en relación con la práctica social que se refleja en ella" (1993, p. 11). Nas CSM, o conceito de justo passa pelas relações sociais representadas ficcionalmente, estabelecendo o contraste entre a expansão da justiça civil, ligada ao projeto

\footnotetext{
${ }^{2}$ As cantigas relacionadas ao tema de castigo e perdão são: $19,35,57,61,72,98,108,117,127$, $154,157,163,164,174$ e 199.
} 
Revista da Seção Judiciária do Rio de Janeiro

imperial de Alfonso $\mathrm{X}$, e a justiça divina, marcada pela intervenção do perdão de Maria para com os malfeitores. No mesmo contexto, há o alastramento do culto mariano por toda a Europa medieval.

As CSM formam um conjunto documental medieval reconhecido pelo seu caráter multifacetário, sobretudo por agruparem diferentes estruturas narrativas em seu corpus: nos campos da poesia, da música, da prosa e da iconografia. Há quatro manuscritos preservados das CSM, datados em sua maioria, provavelmente, do século XIII. Eles estão nomeados como códice j. b. 2 (E), da Biblioteca El Escorial; T. j. I (T), também de El Escorial; o códice de Toledo (To), hoje na Biblioteca Nacional de Madrid; e o manuscrito da Biblioteca Nazionale de Florença (F). Atribuídas ao mecenato do monarca Alfonso X, de alcunha o Sábio, as CSM foram produzidas por um taller de especialistas, muito embora ainda haja discussões quanto à precisão das datas, entre os anos de 1264 e 1284, interrompidas pela morte do rei-Sábio (MONTOYA MARTÍNEZ, 1987, p. 377).

Para tanto, utilizo apenas o códice Rico - deixo o códice de Florença para outra ocasião - por meio da publicação de Walter Mettmann, ocorrida entre os anos de 1959 e 1972, relançadas entre 1986 e 1989, e o fac-símile do mesmo Códice Rico, editado pela Edilán em 1979.

As Siete Partidas (SP) são consideradas não apenas como um corpus documental de características estritamente jurídico, mas também como uma complexa obra que abrange diversas áreas da vida humana. As SP abordam aspectos relativos à conduta, à Igreja cristã, à moral, à guerra, ao matrimônio, ao parentesco, à família, à criação dos filhos, aos papéis sociais dos grupos minoritários (como judeus e muçulmanos) etc. A divisão da obra está em sete partes, sendo que há um resumo daquilo que é tratado em cada partida, título e leis.

A data exata de redação das SP e a comparação com outras obras legislativas do período de Alfonso $X$ são objeto de discussão entre diferentes pesquisadores (ALBERTO PANATERI, 2015; LIMA, 2015; PÉREZ MARTÍN, 1992). São variadas as indicações sobre a elaboração da obra conhecida como SP. Jerry R. Craddock sugere 
Revista da Seção Judiciária do Rio de Janeiro

que os juristas afonsinos trabalharam em uma primeira versão entre junho de 1256 a agosto de 1265, junto com outra versão entre 1272 e 1277 (1981, p. 396). Quanto às fontes das $\mathrm{SP}$, o scriptorium afonsino utilizou textos referentes ao Direito Romano, como o Corpus Iuris Civilis; do Direito Canônico, como o Decreto de Graciano, os Decretais de Gregório IX e o Speculum Iuris de Guilherme Durante; do Direito Feudal, como Libri Feudorum; obras do Direito Leonês e Castelhano, como o Fuero Juzgo, além da Bíblia, os Pais da Igreja e filosofia medieval. Trabalharemos com a edição encomendada à Real Academia de História de Madrid, em 1807, e cotejada por outras fontes medievais castelhanas.

\section{HOMICÍDIO, O ROUBO, A AGRESSÃO FÍSICA E A CALÚNIA NAS CSM}

A primeira cantiga que analiso é uma das mais populares do cancioneiro medieval, ${ }^{3}$ presente em diferentes manuscritos, tanto em romance quanto em latim. Nas CSM está sob o título: Esta é como Santa María fillou vingança dos tres cavaleiros que mataron séu ẽemigo ant' o séu altar, mas nos demais manuscritos é conhecido como "Os três soldados" ou "Os três cavaleiros". Trata-se de um crime cometido por três cavaleiros, sendo um deles "un ric-hóme fól e sobervioso", isto é, rico-homem, louco e soberbo. Aproveitando que um inimigo havia entrado em uma igreja, cujo altar era dedicado à Santa Maria, eles o mataram de forma cruel. Ao tentarem sair da igreja, foram impedidos por Deus por meio de um fogo que veio do céu e que os lançaria para o inferno. Ao se sentirem culpados, e na eminência de irem para a caldeira do Diabo, pediram perdão à Maria, sentiram-se arrependidos e se confessaram ao bispo: "Pois se repentiron, foron mellorados e dun santo bispo mui ben confessados" (ALFONSO X, 1959, p. 58). Como punição, foram exilados na

\footnotetext{
${ }^{3}$ Apenas para citar alguns manuscritos: ms. Phillips (Chicago, University of Chicago, Phillipps, ms. 25142); ms. Thott (Copenhagen, Royal Library, ms. Thott 128); BL Mariale 3 (Londres, BL, Additional, ms. 35112); Lisbon Mariale (Lisboa, B.N., ms. Alcobacense, 149); William of Malmesbury Adgar (Londres, BL, Egerton 612); BL Mariale 2 (Londres, BL, Arundel 346, ff. 60-73); Mariale Magnum (Paris, Bibliothèque Nationale, lat. 3177); Jean Mielot, Miracles de Nostre Dame (Oxford, Bodleian, Douce, ms. 374); Anglo-Norman Miracles of the Virgin (Londres, BL, Royal 20B XIV); Gil de Zamora (Madri, Biblioteca Nacional, ms.9503).
} 
Revista da Seção Judiciária do Rio de Janeiro

Sicília e tiveram que usar cintos apertados à cintura, feitos a partir de suas próprias armas como forma de penitência.

Nota-se que um ponto central é a dialética existente entre o legal e o perdoável como práticas inerentes à própria justiça. No IV Concílio de Latrão ocorrido em 1215, por exemplo, a preocupação com a manutenção da paz pode ser lida no cânone 71 pois, mesmo advertindo que os torneios estivessem proibidos de maneira geral, ainda havia disputas de sangue entre cristãos, o que dificultava fixar acordos entre a nobreza para financiamento da cruzada para Terra Santa:

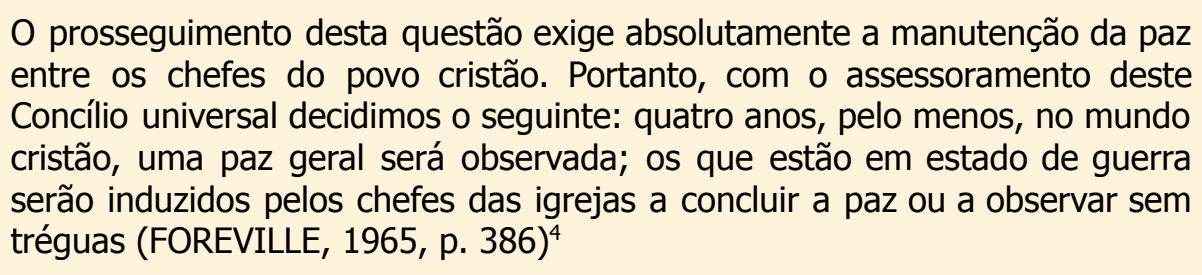

Pelo visto, os apelos de paz da Igreja para com os leigos visavam pavimentar um caminho baseado em armistícios visando alcançar fronteiras mais distantes, como é o caso de Jerusalém. A chamada tregua Dei considerava que os combates em certos períodos do ano, como Advento e Quaresma, passaram a ser vistos como sacrilégio (CARDINI, 2002, p. 479). Ainda há um ponto importante a destacar que é o fato de as SP terem um capítulo específico para tratar dos homicídios. Trata-se do Título VII, de los homeciellos, encontrado no Livro VII. Isso significa que o crime era normativamente previsto e, mesmo que o código afonsino não fosse de uso prático, a presença de uma lei escrita significava que, de alguma forma, mesmo de maneira prototípica, o homicídio era condenado pelo corpo secular.

Segundo o relato da cantiga 19 , houve um assassinato que ocorreu por meio de crueldade, e diante de um altar dedicado à Maria, "... mas ant' o altar con sa gran felonia péças del fezéron per sa pecadillo" (ALFONSO X, 1959, p. 58). A felonia era

\footnotetext{
${ }^{4}$ La poursuite de cette affaire requiert absolument le maintien de la paix entre les chefs du peuple chrétien. Du conseil de ce concile universel, nous statuons donc ceci : quatre années durant pour le moins, dans le monde chrétien, une paix générale sera observée ; ceux qui sont en état de guerre seront induits par les chefs des églises à conclure la paix ou à observer sans défaillance une trêve. [tradução minha].
} 
Revista da Seção Judiciária do Rio de Janeiro

um crime considerado grave porque nele havia traição e deslealdade entre o vassalo e seu senhor, pois esse defeito moral (félon, felão) era um designativo que quebrava a relação de fidelidade vassálica. Apesar da descrição de um crime tão grave, o papel de Maria como interventora e concessora de perdão é fundamental para compreender os contrastes entre amor e justiça. Esse dissenso fica evidente quando se lança um olhar sobre as SP e nelas se lê expressamente que a traição deve ser punida com a morte: "... mas segunt el fucro de España todo home que matase á otro á traycion ó á aleve, quier sea caballero ó otro home, debe morir por ende, segunt dixiemos desuso en el título de las trayciones" (ALFONSO X, 1807, p. 573). É fundamental refletirmos que não se aplica a sentença de morte na cantiga 19 , a punição estabelecida mortal não foi efetivada porque os criminosos se arrependeram diante da possibilidade de irem para o inferno, graças à intervenção mariana.

Seguindo as narrativas alfonsinas que abordam o tema do perdão, a cantiga 57 trata da história dos ladrões que roubaram uma dama que estava de passagem pela montanha de Montserrat, atual Catalunha. O prólogo da cantiga é conhecido como Esta é como Santa María fez guarecer os ladrões que foran tolleitos porque roubaran ũa dona e sa companna que ían en romaría a Monsarrat. A palavra tolleito significa, segundo o "Dicionario de dicionarios do Galego Medieval", paralisado5. Isso ocorreu porque, após o roubo, a dama foi à cidade de Montserrat e tornou público o acontecido, "Virgen santa, Reínna, dá-me vingança, ca pris viltança en ta romaría" (ALFONSO X, 1959, p. 162). Alguns religiosos encontraram os ladrões em um declive na serra em situação deplorável, em estado de paralisia, surdos, mudos e a comida que tentavam engolir ficava presa na garganta, pois "... que dentro nen afóra non podía sacá-la, nen comer nen passá-la" (ALFONSO X, 1959, p. 163). Os freis levaram os malfeitores em seus cavalos até a cidade e lhes fizeram orações. Com isso, foram

\footnotetext{
${ }^{5}$ É possível consultar novos dicionários da língua galega-portuguesa medieval no portal eletrônico dicionario de dicionarios do galego medieval, coordenado por Ernesto González Seoane, María Álvarez de la Granja e Ana Isabel Boullón Agrelo do Instituto da Lingua Galega. Há, neste portal, a possibilidade de se cotejar diferentes dicionários e traduções ao buscar um dado corpus lexicográfico medieval. Ver: http://sli.uvigo.es/DDGM.
} 
Revista da Seção Judiciária do Rio de Janeiro

se recuperando e, ao fim, arrependeram-se e juraram que nunca mais roubariam cristãos.

Há pelo menos dois crimes previstos na legislação alfonsina: o roubo em si e a importunação a peregrinos. Desde o século XII, uma primeira normativa civil em terra hispânica buscava resguardar os peregrinos para que não houvesse penhora de bens por parte de mercadores, sob pena de excomunhão e multa (GALLEGOS VÁZQUEZ, 2005, p. 98), evidenciando uma crescente preocupação para a manutenção da paz aos que desejassem fazer peregrinação. Já no século XIII, Alfonso $\mathrm{X}$ legislou sobre a segurança de romeiros e peregrinos, como se vê no Título 14, da Primeira Partida: "Onde los ornes que con tan buena intención, e tan santa, andan por el Mundo, derecho es, que mientras en esto andovieren, que ellos e sus cosas sean guardados, de manera, que ninguno non se atreva de ir contra ellos, faciendo les mal." (ALFONSO X, 1807, p. 497). Alfonso X se preocupou com as variadas rotas de peregrinação do Reino de Castela e Leão, e mesmo Montserrat estava sob domínio de seu sogro, Jaime II. As disputas sobre a popularidade dos caminhos peregrinatórios fazem parte de outra discussão que não abordarei aqui.

O roubo, como disse, era outro crime punido com extremo rigor. A cantiga narra que o cavaleiro que assaltou a dama se chamava Raimundo e levou todo o dinheiro dos caminhantes "... eles mui correndo saiu ben desse monte e Reimund', un cavaleiro roubador e guerreiro, que de quanto tragían non lles leixou dinneiro que non roubasse e non fillasse con sa compannía" (ALFONSO X, 1959, p. 162). Nota-se que, além do sacrilégio de interromper a viagem dos romeiros, os assaltantes cometeram o roubo, também previsto nas $\mathrm{SP}$, inclusive com uma definição prévia sobre o que é o ato de roubar, como descrito na Partida Sétima, Título 13, Ley I: "... es quando alguno roba á otro lo suyo ó lo que levase ageno, en poblado ó en yermo, non habiendo razon derecha por que lo debe facer" (ALFONSO X, 1807, p. 605). Em geral, as penas variavam dentro daquilo que se entendia como pena de pecho, isto é, de obrigação pecuniária, em que o criminoso deveria ressarcir a vítima. Assim sendo, o ladrão que praticou algum tipo furto ou roubo deveria indenizar a vítima de 
Revista da Seção Judiciária do Rio de Janeiro

acordo com a coisa roubada devolvendo em três vezes o valor: "La primera es de pecho; ca el que roba la cosa es tenudo de tornarla con tres tanto de mas de quanto podria valer la cosa robada" (ALFONSO X, 1807, p. 605). A segunda dependeria da forma e contra quem foi cometido o crime, sendo alterável a condenação, podendo ir do açoite ou até mesmo à pena de morte. Na Ley XVIII, Qué pena merecen los furtadores et los robadores, está explícito que quem rouba o rei, membros da realeza, lugares ou coisas sagradas deveria morrer: "... debe morir por ende él et todos quantos dieron ayuda ó consejo á tales ladrones en facer el furto, de los encubriesen en sus casas ó en otros lugares, deben haber aquella misma pena" (ALFONSO X, 1807, p. 617-618). Vale considerar que, embora as Partidas busquem diferenciar roubo de furto, ao longo das argumentações dos títulos da Sétima Partida, parece que ambos se confundem.

Voltando à cantiga 57, os criminosos receberam o perdão da Virgem Maria ao se arrependerem de seus crimes. Depois que recuperaram a visão e a saúde, juraram não praticar mais crimes contra cristãos, "... e por ende juraron que nunca a crischãos jamais roubassen, e se quitassen daquela folía." (ALFONSO X, 1959, p. 163). Mais uma vez, a justiça secular, representada parcialmente por meio das SP, não condenou os criminosos dentro dos limites das leis vigentes em seus fueros reais. A intervenção milagrosa foi responsável pela redenção dos infratores. Voltarei a essa questão mais à frente.

Seguindo os relatos que tratam de punição e perdão, destaca-se o milagre 127 intitulado Esta é como Santa María non quis que entrasse na sa eigreja do Poe un mancebo que déra a sa madre un couce; e el, pois viu que non podía entrar, cortou o pée, e depois sãou-o Santa María. A história narra que um jovem deu uma surra em sua mãe, cujo relato afirma que se tratava de uma boa senhora "... con sa madre que havía bõa fora barallar" (ALFONSO X, 1961, p. 74). Maria deu a ele como castigo uma grande dor e lhe impôs que fosse de joelhos até a igreja de Puy em romaria. Logo na entrada do templo, o mancebo não pode entrar porque Maria não havia permitido. As pessoas do lugar tentaram empurrá-lo, mas não conseguiram 
Revista da Seção Judiciária do Rio de Janeiro

movê-lo. Os clérigos do local, vendo aquela situação, pediram que o jovem se confessasse. Logo que contou o que tinha feito, aconselharam-no a cortar os seus próprios pés para entrar na igreja, o que foi feito imediatamente. No interior da igreja, a mãe, vendo seu filho sem os pés, pediu que Maria o perdoasse: "Santa María, Sennor, pois que vin a ti, non queiras que o méu fillo sen pée vaa daquí" (ALFONSO X, 1961, p. 74). Em um sonho, Maria disse que recolocasse o pé no lugar que seria sanado, o que ocorreu quando a mãe acordou do sono.

Nas SP há uma introdução na Partida IV, Título 2, Ley II, sobre a dor das mães ao parirem seus filhos. Trata-se do capítulo sobre matrimônio, o qual busca-se justificar porque a união entre marido e mulher não se chama patrimônio:

\begin{abstract}
Et la razon porque llaman matrimonio al casamiento et non patrimonio es esta, porque la madre sufre mayores trabajos con los fijos que non el padre; ca como quier quel padre los engendre, la madre sufre grant embargo con ellos demientre que los trae en el vientre, et sufre muy grandes dolores quando ha de encaescer: et despues que son nascidos lieva muy grandes trabajos en criarlos ella por sí mesma: et demas desto porque los fijos demientre que son pequeños, mas meester han el ayuda de la madre que del padre. Et porque todas estas razones sobredichas caen á la madre de facer et non al padre, por ende es llamado matrimonio et non patrimonio (ALFONSO X, 1807, p. 12).
\end{abstract}

Para leitura atenta das SP convém ao leitor não imaginar que há uma valorização das mulheres em um sentido moderno do termo, ou seja, o reconhecimento pelo trabalho de maternagem, ou mesmo com alguma espécie de igualdade de gênero. Ao longo da obra legislativa alfonsina, verifica-se que o casamento proposto por essa normativa recoloca o filho, em especial o primogênito, como herdeiro principal, excluindo as mulheres dos espólios familiares. Dito isso, a cantiga 157 fala em uma punição corporal ao mancebo, com a perda dos pés, mas não identifiquei nas SP a premência desse castigo corporal a alguém que causa mal à própria mãe, o que não é incomum, pois as CSM são um conjunto heterodoxo de acontecimentos que vai além das premissas jurídicas vigentes. 
Revista da Seção Judiciária do Rio de Janeiro

A última cantiga que abordo é a que trata da cunhagem ilegal de moedas. Trata-se da cantiga 164, que tem como prólogo Como a omage de Santa María de Salas déu ũu braado, e tremeu a térra, por un prïor da eigreja que fez tirar a força do sagrado Don Fernando, abade de Montaragôn. Vale ressaltar que se trata de um relato localizado geograficamente e pertence ao ciclo de coleções alfonsinas que fazem referências aos milagres do santuário de Santa Maria de Salas. A igreja de Salas está localizada hoje na província homônima de Huesca, na Comunidade Autônoma de Aragão, Espanha. A fundação da igreja data do século XII. Não se sabe exatamente a qual repertório de milagres marianos este conjunto de cantigas foi tributário. É muito difícil identificar quais as fontes que ofereceram as histórias ao scriptorium alfonsino. António Ubieta Arteto supõe que havia um conjunto de manuscritos latinos de milagres em Huesca, mas essa documentação se perdeu. 0 autor espanhol parte da toponímia e sugere que o nome de um lugar chamado Petrasalze, que aparece na cantiga 164, seja "Pedra selze", uma latinização do nome de um povoado em Huesca chamado Piracés (UBIETA ARTETO, 1989, p. 619).

A história alfonsina narra que o prior de Salas havia sido acusado de mandar forjar moedas. Quando o infante de Montearagón, que também tinha sido abade, soube de tal crime, mandou prender o religioso, que tentou se refugiar na igreja, acreditando que ali estaria seguro. 0 infante parou em frente à igreja e mandou o acusado sair para ser enforcado no cemitério. Mas todos que estavam ali ouviram um grito muito forte que fez tremer a terra. Nisso, todos viram a imagem do menino Jesus se separar da mãe, Maria, e a estátua do altar perder a cor. Todos voltaram para o interior da igreja, quando surgiu o bispo de Huesca que, vendo toda aquela confusão, entendeu que o monge era inocente. Ao reunir-se novamente o Filho à Mãe, os presentes entenderam que Maria havia perdoado aquela falsa acusação.

Nas SP, o crime de cunhagem de moedas não apenas estava previsto como uma infração grave, e há que sublinhar que o crime de falsificação estava vinculado ao crime de traição ao rei, mas cuja tipificação era considerada irreparável e passível de pena de morte. A justificativa para proibição era de que apenas a autoridade 
Revista da Seção Judiciária do Rio de Janeiro

poderia produzir numerários: "Moneda es cosa con que marcan et viven los homes en este mundo; et por ende non ha poderío de la mandar facer ningunt home sí non fuere emperador, ó rey ó aquellos á quien ellos otorgan poder que la fagan por su mandado" (ALFONSO X, 1807, p. 564). Não por menos, fraudar metais circulantes era objeto de ampla e detalhada legislação. Na Sétima Partida, Título 2, Ley I, a definição de traição é a seguinte: "Et traycion es la mas vil cosa et la peor que puede caer en corazon de home: et nascen della tres cosas que son contrarias de la lealtad, et son estas: tuerto, et mentira et vileza" (ALFONSO X, 1807, p. 538). Das várias formas de traição, a falsificação de moedas ou selos reais fazem parte do rol de crimes chamados lesa-majestade, cujo tratamento dado ao culpado é exemplar, pois qualquer pessoa que cometer deslealdade "... debe morir por ende, et todos sus bienes debenseer de la cámara del rey, sacada la dote de su muger, et los debdos que hobiese á dar" (ALFONSO X, 1807, p. 540). Além disso, os filhos seriam afamados, isto é, considerados indignos moralmente. Tanto era considerado uma transgressão preocupante que a cantiga afirma que o prior ia ser levado à morte ao ser enforcado rapidamente no cemitério quando o infante o chamou para fora da igreja, "... fez-lo de fóra chamar, e pois que saiu a ele, mandó-o ben recadar, e assí o fez per força do cimiteiro tirar" (ALFONSO X, 1961, p. 164), situação que foi interrompida pela intervenção de Maria.

Entretanto, curiosamente, a cantiga 164 não aborda a cunhagem de moedas como a violação mais grave, nem mesmo a detração, ao acusarem o monge injustamente de trair o rei. Há que se recordar que ouviram dizer que o monge fazia moedas "Este monge acusado fora aquela sazón de mandar fazer moeda e por aquesta razón fez-lo prender o ifante que foi de Mont-Aragón abade e que a térra tínna acomendada" (ALFONSO X, 1961, p. 164). Trata-se de outro crime cuja tipificação moderna é chamada de calúnia. Na Quarta Partida há uma detalhada descrição sobre o que é testemunho e quais são as circunstâncias em que se pode manifestar esse tipo de acusação e, sobretudo, quais as pessoas honradas o suficiente para testificar. Pode-se verificar que quem oferece falso testemunho é 
Revista da Seção Judiciária do Rio de Janeiro

passível de castigo porque prejudica aos outros e contamina todo o processo, como descreve a Terceira Partida, Título 16, Ley XLIII: "Pena muy grande merescen los testigos que á sabiendas dan falso testimonio contra otri, ó que encubren la verdat por engaño ó por malquerencia que hayan contra algunos" (ALFONSO X, 1807, p. 538). Ao longo da cantiga 164, não identificamos quais pessoas levantaram falso testemunho, pois esta informação não está no relato poético. Apenas nas imagens a silhueta dos personagens que fizeram a intriga aparece:

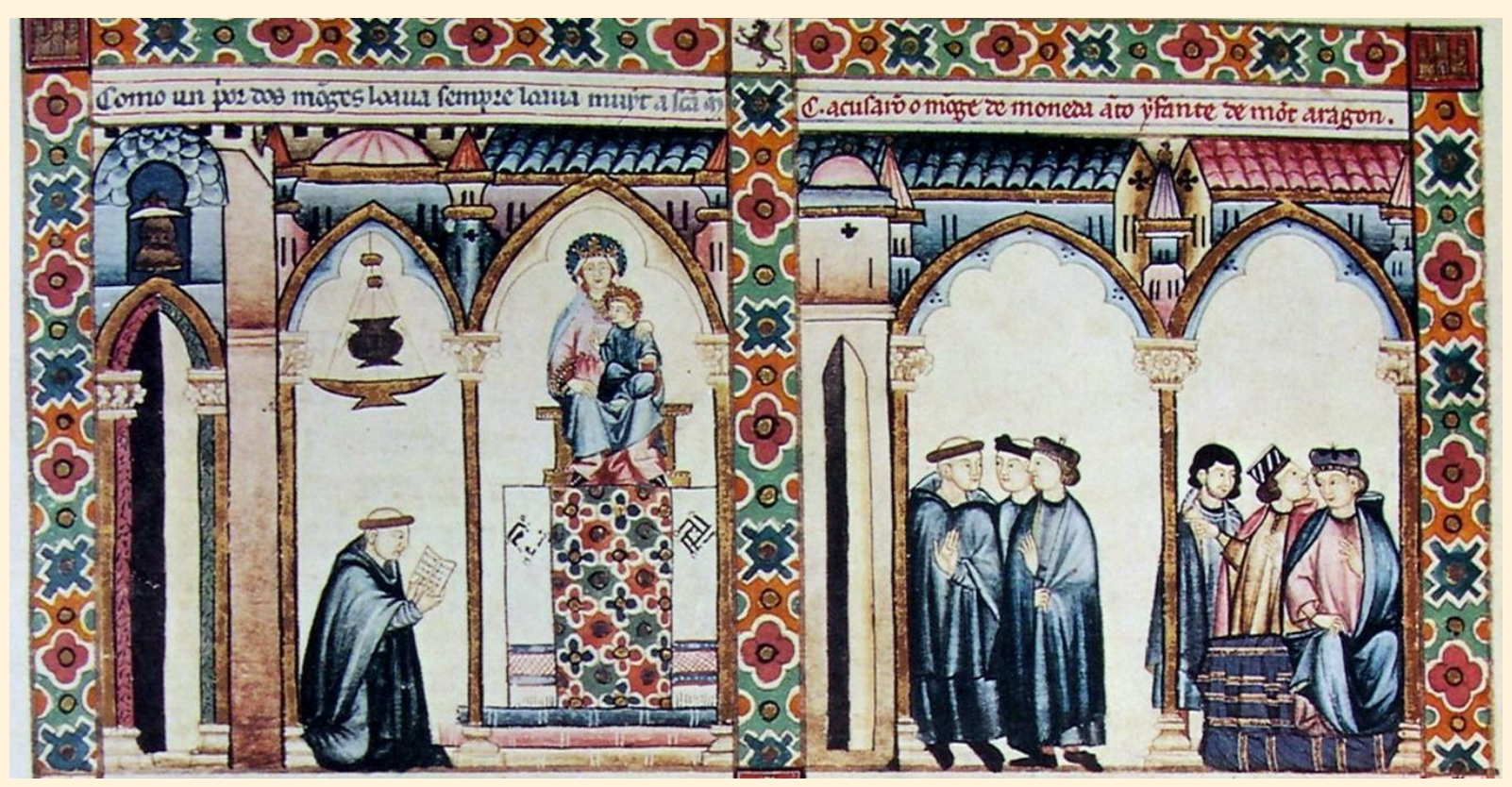

Imagem 01: cantiga 64, As Cantigas de Santa Maria - Códice Rico de El Escorial T-I-1 - E2, f. $29 \mathrm{v}$, miniaturas $1 \mathrm{~A}$ e $2 \mathrm{~B}$

Nos primeiros rótulos da imagem, pode-se ler "Como um prior dos monges loava sempr' e loava muit' a Santa Maria", isto é, condiz com o relato textual da cantiga ao destacar que o monge era dedicado ao culto mariano. É possível observar que o prior está lendo um livreto, provavelmente um saltério, diante do altar de Maria. Já na segunda vinheta, a cena da denúncia contra o monge lhe acusando de falsificar moedas é captada no exato instante em que um personagem aponta o dedo em direção ao suspeito. Sobre a cena se pode ler: "Como acusarom o monge de 
Revista da Seção Judiciária do Rio de Janeiro

mõeda ant' o ifante de Mont' Aragom". Provavelmente o primeiro com a cabeça tonsada é o mesmo personagem da primeira vinheta e, possivelmente, a leste, sentado em uma poltrona confortável, é o infante.

\section{CONSIDERAÇÕES FINAIS}

Nas SP há especificamente um esforço para que se busque o senso de justiça. Como afirma Jessica Knauss, as SP não consideram apenas a justiça formalizada nos tribunais, mas as maneiras de se manter a ordem na sociedade em todas as situações (2011, p. 58). Tanto que, especialmente, nas SP a noção de justiça divina e justiça real se confundem e acabam por se fundirem, fruto provavelmente do papel que tinha a Bíblia como documento fundador e ordenador dos preceitos simbólicos acerca das condutas humanas. Na Segunda Partida há uma extensa exposição daquilo que deve fazer o imperador como guia da sociedade, orientando e protegendo o reino, como sugere a Partida Segunda, Título 1, Ley V: "Vicarios de Dios son los reyes cada uno en su regno puestos sobre las gentes para mantenerlas en justicia et en verdad quanto en lo temporal, bien así como el emperador en su império" (ALFONSO X, 1807, p. 7). Aqui o sentido de justiça se vincula à noção de "direito natural", ou seja, a argumentação central é a de que o rei é a cabeça da sociedade e dela nascem os sentidos que, em seguida, comandam os membros do corpo:

\footnotetext{
Et naturalmente dixieron los sabios que el rey es cabeza del regno; ca así como de la cabeza nacen los sentidos por que se mandan todos los miembros del cuerpo, bien así por el mandamiento que nace del rey, que es señor et cabeza de todos los del regno, se deben mandar, et guiar et haber un acuerdo con él para obedescerle, et amparar, et guardar et endereszar el regno onde él es alma et cabeza, et ellos los membros (ALFONSO X, 1807, p. 7-8).
}

Essa ideia de um império que se confundia com o universo simbólico não é novidade para os medievalistas. Basta lembrar dos pressupostos teóricos de Ernst $\mathrm{H}$. 
Revista da Seção Judiciária do Rio de Janeiro

Kantorowicz em seu clássico "Os dois corpos do rei" (1998). Ao longo do século XIII, o repertório simbólico da Igreja foi sendo apropriado pelo Estado, naquilo que ficou conhecido como "corpo místico da república", em referência ao texto de Vincent de Beauvais, corpus republicae mysticum, em que há fartas ideias eclesiásticas sendo emprestadas para o corpo político secular. Kantorowicz destaca que a ideia do rei como vicário de Cristo, além de representante dos elementos antes pertencentes ao universo institucional cristão, há também a ideia de cabeça de um corpo social: "A noção de corpus mysticum significa, em primeiro lugar, a totalidade da sociedade cristã em seus aspectos organológicos: um corpo constituído de cabeça e membros" (1998, p. 134). Isso quer dizer que os autores das SP compartilhavam as preposições que amalgamam as diferentes visões eclesiásticas e seculares, produto das compilações jurídicas, do crescimento universitário, do surgimento das corporações de ofício, do desenvolvimento das cidades e da secularização dos corpos políticos.

Já nas CSM a ideia de justiça é mais fluida e condiz com a maneira como foram compiladas as coleções de milagres, isto é, a partir de diferentes fontes, principalmente em francês e latim, os colaboradores traduziam os conteúdos e sumarizavam os textos. Um processo similar e paralelo deve ter sido feito para transformação das histórias textuais em miniaturas e notações musicais. Em seguida, após a etapa de compilação, havia a composição das cantigas e, provavelmente, um processo de elaboração dos códices na construção das epígrafes, índices, legendas para painéis individuais nas miniaturas, introdução de material textual adicional, e/ou a recomposição, ou seja, quando uma cantiga precisou ser modificada (PARKINSON; JACKSON, 2006, p. 160). Com isso, mesmo atentando para uma coordenação de um projeto unificado, a coleção de milagres traduz múltiplas experiências oriundas de contextos singulares que precisaram ser reunidos em um único códice.

Dito isto, convém sublinhar que as CSM, para além das diferenças entre as histórias, possuem um eixo norteador: o papel de Maria no livramento da punição a que deveria ser submetido o criminoso. Dessa forma, a ideia de pecador, ao menos nas cantigas aqui analisadas, é mais presente que a noção de criminoso. Nota-se que 
Revista da Seção Judiciária do Rio de Janeiro

os transgressores de fato cometeram crimes previstos em lei, mas foram absolvidos por determinação de Maria. A justiça divina é invocada para livrar o condenado da justiça secular, o que coloca em questão o problema destacado por Paul Ricoeur de que as circunstâncias da justiça são uma atividade comunicativa, isto é, solicita-se a uma instância superior "... resolver entre reivindicaciones (claims) de partes portadoras de interesses o de derechos opuestos" (1993, p. 22). Para tanto, precisa-se de canais de justiça: um aparato judicial formado por leis escritas, tribunais de justiça, pessoas investidas da função de ditar o direito, juízes, ".... individuos como nosotros, considerados independientes, y encargados de pronunciar la sentencia justa en uma circunstancia particular" (RICOEUR, 1993). Já o amor, no caso das cantigas o amor mariano, não precisa do formalismo da justiça nem dos argumentos comunicativos seculares. Nas CSM, o homicídio, o roubo, a agressão física e a calúnia são perdoadas mediante compensações que variam do cumprimento de normas eclesiásticas (como a confissão), do arrependimento e da penitência (como fazer uma romaria).

Resta levantar a seguinte problematização: em que repousa o contraste entre a norma escrita das SP e a fluidez oralizante das CSM? O projeto político de Alfonso $\mathrm{X}$ o coloca entre o justo e o benevolente. Alfonso $\mathrm{X}$ foi um dos candidatos ao trono do Império Germânico na ocasião da morte de Federico II, em 1250. Como o Império se estendia até a Sicília, a cidade de Pisa enviou um "embaixador", Bandino di Guido Lancia, para Castela para tentar admoestar Alfonso X para que assumisse o trono germânico em 1256, visto que o filho de Federico II perdeu seu filho-herdeiro em 1254, Conrado IV. Por razões diversas, isso não ocorreu. No entanto, Alfonso X foi um monarca mecenas, agenciador de projetos ligados à chamada Reconquista, com as campanhas de Murcia e Sevilla, por exemplo, e as relações, muitas vezes conflituosas, com o papado. Em verdade, temos que ver as obras alfonsinas como um todo que, embora não unificado, dialogam entre si. Logo, a justiça baseada no perdão, no amor divino, contrasta com a justiça secular, mas, ao mesmo tempo, reposiciona o monarca como alguém dotado de clemência e signatário do crescente 
Revista da Seção Judiciária do Rio de Janeiro

culto mariano a partir do século XIII. De qualquer forma, Alfonso $\mathrm{X}$ intertextualizou seus discursos para ação política, executando um programa de poder político e cultural. 
Revista da Seção Judiciária do Rio de Janeiro

\section{REFERÊNCIAS}

ALBERTO PANATERI, Daniel. Voces jurídicas disímiles y discurso político monárquico, el caso de Partidas y su edición de 1555. Medievalia, Barcelona, v. 18, n. 1, p. 59-86, 2015.

ALFONSO X, O SÁBIO. As Cantigas de Santa Maria - Códice Rico de El Escorial T-I-1 - E2. Madrid: Edilán, 1979.

ALFONSO X, O Sábio. As Cantigas de Santa Maria. Coimbra: Acta Universitatis Conimbrigensis, 1959. v. I.

ALFONSO X, O Sábio. As Cantigas de Santa Maria. Coimbra: Acta Universitatis Conimbrigensis, 1961. v. II.

ALFONSO X, O Sábio. Las Siete Partidas del Rey Don Alfonso el Sabio, cotejadas con varios códices antiguos por la Real Academia de la Historia. 3 tomos. Madrid: Imprenta Real, 1807.

CARDINI, Franco. Guerra e Cruzada. In: GOFF, Jacques; SCHMITT, Jean-Claude (dir.). Dicionário Temático do Ocidente Medieval. Bauru: EDUSC, 2002. v. 2. p. 473-487.

CRADDOCK, Jerry R. La cronología de las obras legislativas de Alfonso $x$ el Sabio. Anuario de Historia del Derecho Español, [s. I.], n. 51, p. 365-418, 1981.

FILGUEIRA VALVERDE, José. As Cantigas de Santa Maria. Madrid: Castalia, 1985.

FOREVILLE, Raymonde. Latran I, II, III et Latran IV. Paris: Éditions de L'orante, 1965.

GALLEGOS VÁZQUEZ, Federico. Estatuto jurídico de los peregrinos en la España medieval. Santiago de Compostela: Xunta de Galicia, 2005.

KANTOROWICZ, Ernst. Os dois corpos do rei: um estudo sobre teologia política medieval. São Paulo: Companhia das Letras, 1998.

KNAUSS, Jessica. Law and Order in Medieval Spain - Alfonsine Legislation and the Cantigas de Santa Maria. Tucson: Açedrex Publishing, 2011.

LIMA, Marcelo Pereira. Comparando a fabricação de códigos afonsinos: o Especulo, o Fuero Real e as Siete Partidas. Revista de História Comparada, Rio de Janeiro, v. 9, n. 1, p. 06-42, 2015. 
Revista da Seção Judiciária do Rio de Janeiro

MONTOYA MARTÍNEZ, Jesús. Algunas precisiones de las Cantigas de Santa María. In: KATZ, Israel J. e KELLER, John E. (orgs). Studies on the Cantigas de Santa Maria: Art, Music, and Poetry. Madison: Associate Editors Samuel G. Armistead \& Joseph T. Snow, 1987. p. 367-386.

PARKINSON, Stephen; JACKSON, Deirdre. Collection composition and the compilation in the Cantigas de Santa María. Portuguese Studies, Londres, v. 22, n. 2, p. 159-172, 2006.

PÉREZ MARTÍN, António. Fuentes romanas en las Partidas. Glossae: European Journal of Legal History, n. 4, p. 215-246, 1992.

RICOEUR, Paul. Amor y Justicia. Madrid: Caparros, 1993.

UBIETA ARTETO, António. Las cantigas de Alfonso X el Sabio relativas a Santa María Salas - Huesca. Mayurqa, vol. 22, n. 2, p. 615-622, 1989. 